\title{
Fonologia em perspectivas: Modelos Gerativos, Fonologia Prosódica e Modelo de Exemplares
}

\author{
Isabela Prisco PETRY (D) \\ Universidade Federal do Rio Grande do Sul (UFRGS)
}

Pedro Eugênio GAGGIOLA (®

OPEN ACCESS

Universidade Federal do Rio Grande do Sul (UFRGS)

EDITADO POR

Raquel Freitag

AVALIADO POR

Carmen Matzenauer

SOBRE OS AUTORES

Isabela Prisco Petry

Contribuiu com Pedro

Eugênio Gaggiola. Papéis: conceptualização, escrita -

análise e edição.

Pedro Eugênio Gaggiola

Contribuiu com Isabela

Prisco Petry. Papéis:

conceptualização, escrita -

análise e edição.

DATAS

Recebido: 04/08/2020

Aceito: 04/09/2020

Publicado: 15/09/2020

COMO CITAR

Petry, I. P.; Gaggiola, P. E. (2020). Fonologia em perspectivas: Modelos Gerativos, Fonolo-

gia Prosódica e Modelo de Exemplares. Revista da Abralin,

v. 19, n. 2, p. 1-5, 2020.

\section{RESUMO}

A presente resenha parte da mesa redonda composta pelas professoras doutoras Carmen Matzenauer, Luciani Tenani e Christina Abreu Gomes, coordenada por José Magalhães e promovida pelo evento Abralin Ao Vivo. A mesa versa sobre diferentes perspectivas da Fonologia, em homenagem à ilustre linguista Leda Bisol. Inicia-se, então, com a fala da professora Carmen Matzenauer, sobre Fonologia Gerativa e seus aspectos principais, como níveis de representação, regras e traços. A professora apresenta dados de aquisição da linguagem, além de desdobramentos dessa Fonologia em Fonologias Não Lineares. A seguir, a professora Luciani Tenani faz uma interessantíssima apresentação quanto ao sândi vocálico, sob a perspectiva da Fonologia Prosódica no domínio da Fonologia Gerativa. Para finalizar, a professora Christina Abreu Gomes apresenta uma proposta baseada no Modelo de Exemplares, discorrendo sobre o conceito de não separação entre léxico e gramática e sobre os efeitos de frequência de types e tokens no uso da língua.

\section{ABSTRACT}

This review is based on the roundtable conference promoted by professors Carmen Matzenauer, Luciani Tenani and Christina Abreu Gomes and coordinated by professor José Magalhães, aiming to discuss various perspectives in the field of phonology, in honor of the outstanding linguist 


\section{REVISTA DA ABRALIN}

Leda Bisol. A lecture given by Carmen Matzenauer on Generative Phonology and its main assumptions (e.g. levels of representation, rules and features) initiates the roundtable conference, in which she presents language acquisition data and discusses some ramifications of Generative Phonology, specifically Nonlinear Phonology. Furthermore, Luciani Tenani presents interesting examples concerning vocalic sandhi in Brazilian Portuguese based on assumptions derived from Prosodic Phonology located in the domains of Generative Phonology. Eventually, Christina Abreu Gomes discusses Exemplar-based models applied to phonological theory, referencing the continuity between lexicon and grammar proposed by these models as well as presenting effects of type and token frequencies in the use of language.

PALAVRAS-CHAVE

Fonologia Gerativa. Fonologia Prosódica. Modelo de Exemplares.

KEYWORDS

Generative Phonology. Prosodic Phonology. Exemplar Model.

A mesa redonda aqui resenhada, intitulada Fonologia, foi composta pelas professoras doutoras Carmen Matzenauer (UFPEL), Luciani Tenani (UNESP/S. J. Rio Preto) e Christina Abreu Gomes (UFRJ) no dia 29 de julho de 2020 no evento Abralin Ao Vivo -Linguists Online, promovido pela Associação Brasileira de Linguística (Abralin). A mesa foi coordenada por José Magalhães (UFU) e desenvolvida como uma homenagem à exímia linguista Leda Bisol.

Inicia-se a mesa com a moderação do professor José Magalhães, que ressalta as contribuições fundamentais de Leda Bisol, professora emérita pela UFRGS, para os estudos em Fonologia do português brasileiro. Em seguida, as bases estruturalistas da Fonologia no campo da linguística sincrônica são relembradas pelo professor, destacando desde as contribuições de Roman Jakobson para a noção de fonema como uma entidade opositiva abstrata, passando pela reformulação teórica proposta pelo The Sound Pattern of English de Chomsky e Halle (1968), até à proposta de abandono de concepções discretas para o fonema trazida pela Fonologia nos Modelos de Exemplares.

Em seguida, a professora Carmen Matzenauer fala sobre a Fonologia Gerativa como um marco nos estudos da gramática fonológica das línguas e apresenta as seguintes duas razões para assim considerá-la: constituiu um novo paradigma conceitual e metodológico e possibilitou desdobramentos desde a Fonologia Gerativa Clássica aos modelos de Fonologias não-lineares. Introduzindo a Fonologia Gerativa, a professora diz que a Fonologia Gerativa visa a uma descrição da gramática fonológica, buscando formular uma teoria da língua com seus padrões e variações (LEE, 2017). 


\section{REVISTA DA ABRALIN}

Apresenta, então, os níveis de representação: (i) representação subjacente (fonológica), que é composta pelo input (ex. / karta/), seguida pelas regras fonológicas, que são aplicadas de maneira ordenada pelo falante (ex. acentuação 'kar.ta; alçamento e centralização da átona final 'kar.te) e revelam generalizações sobre a fonologia da língua e (ii) a representação de superfície (fonética), que ganha mais atenção na Teoria da Otimidade, uma vez que é constituída pelo output (ex. ['kartø]). É importante destacar que as regras têm um papel fundamental para a Fonologia Gerativa, já que implicam necessariamente a existência de dois níveis de representação, como aponta a professora.

Hyman (1975), citado por Matzenauer, dizia que era necessário buscar evidências para essa representação tão abstrata. $\mathrm{O}$ autor explicita quatro: a intuição linguística, o sotaque estrangeiro, os lapsos de fala e a aquisição da linguagem. A partir desta, a professora traz quatro exemplos, dos quais explorarei dois a seguir. O primeiro é o fenômeno FIS, em que um menino de três anos (3:0) produz Capitão Gancho como Capitão Gan[s]o, mas quando escuta um adulto falar assim, rejeita: Não é Gan[s]o! é Gan[s]o!, ou seja, a percepção (fonológica) diferencia-se da produção (fonética). O segundo exemplo é de uma menina (2:6), que, como na fala adulta de seu contexto, vocaliza lateral em coda de sílaba, mas que ainda não tem, integrada ao seu inventário fonético, a rótica nessa posição. A partir disso, ela produz [aw'mosv] e ['poltr], evidenciando que, na representação fonológica, sabe que a líquida na coda de porta é outra que não a lateral.

A seguir, a professora faz uma apresentação dos traços, tanto fonológicos, quanto fonéticos, que compõem paradigmaticamente cada palavra. Ela elucida que as regras se aplicam a conjuntos nãoarbitrários de traços, ou seja, às classes naturais. Apesar da concepção de traços da Fonologia Gerativa ter sido muito importante, apresentava também muitas limitações (ex. falta de hierarquia entre os traços, matriz indissociável, entre outras). Por causa disso, surgiram as Fonologias Não Lineares, como a Autossegmental, na qual os traços não compõem mais matrizes individuais correspondentes a um único fonema, diferentemente do que se observa no SPE.

Seguindo com o intuito de apresentar importantes vertentes de análises fonológicas, a professora Luciani Tenani localiza a Fonologia Prosódica no domínio da Fonologia Gerativa, mais especificamente como um modelo não linear de análise prosódica. A epistemologia adotada organiza sons em constituintes hierárquicos dependentemente relacionados e submetidos a princípios comuns às línguas naturais. Dados empíricos do português brasileiro são apresentados à luz do modelo relation-based (NESPOR; VOGEL, 1986), assumindo que relações sintáticas atuam na estrutura prosódica.

A aplicabilidade do sândi vocálico (BISOL, 1992) é retomada para justificar a existência do constituinte prosódico relativo ao sintagma fonológico. Vogais iguais átonas adjacentes licenciam degeminação, como se vê no exemplo alun[a]fricana (as notações aqui usadas serão fiéis às apresentadas pela professora). O processo se torna variável se a primeira vogal envolvida for tônica, como no exemplo maraj[á] [a]fricano, que resulta em maraj[á]fricano variavelmente. O sândi vocálico é impedido quando a segunda sílaba for portadora de acento, não sendo possível realizar alun[á]rabe. O último fato apresentado é, em seguida, revisto em termos de relações prosódicas e não mais com base exclusiva em relações entre sílabas. O sândi vocálico é impedido, de acordo com a professora, quando a segunda sílaba envolvida no processo de degeminação for portadora da proeminência acentual do sintagma 


\section{REVISTA DA ABRALIN}

fonológico, justificando a aplicação variável da regra em (1) [a aluna] [árabe-marroquina], uma vez que árabe não carrega a proeminência do sintagma fonológico (indicado por colchetes) nesse contexto prosódico. A configuração, a nível silábico, não se modifica: o contexto da possível degeminação continua sendo composto por uma primeira vogal átona idêntica a uma segunda vogal tônica. O que possibilita a aplicação da regra em um contexto como (1) está no âmbito da prosódia: a segunda sílaba do processo não porta mais a proeminência acentual do sintagma. A variação dependente de contexto prosódico exemplificada justifica a realidade do sintagma fonológico.

A relevância do sintagma fonológico é também elucidada por contextos nos quais há choque de acento. A mudança posicional do acento é possibilitada em (2) [[café quente]థ]I movendo o acento da primeira palavra fonológica da última para a penúltima sílaba se ambas as palavras fonológicas integrarem um mesmo sintagma fonológico, como é o caso de (2), solucionando o encontro de acentos adjacentes. O exemplo (3) [[café] $\Phi$ [queima] $\Phi]$ i ilustra um contexto no qual a mudança de posição do acento na primeira palavra fonológica é impossibilitada por conta de as palavras fonológicas em questão não integrarem um sintagma comum. A Fonologia Prosódica, assim, objetiva predizer a organização fonológica do enunciado também com base em informação sintática, como aqui ilustrado.

A professora Christina Abreu Gomes integra o debate apresentando uma proposta à fonologia baseada no Modelo de Exemplares. Primeiramente, assegura as bases epistemológicas do modelo abordado, iniciando pela premissa de que a experiência sensorial do indivíduo é detalhadamente armazenada em estruturas neuronais, sendo o conhecimento linguístico registrado de forma comum às demais experiências. A cronologia da concepção da inclusão do detalhe em representações mentais é apresentada, enfatizando a ideia de Johnson (1997) a respeito da resistência de informações gradientes nos sistemas de memória, não sendo removidas por completo em processos de abstração, ainda que o fenômeno da normalização seja reconhecido, ou seja, ainda que haja atenuação de diferenças acústicas (motivadas por razões fisiológicas, por exemplo) entre falantes.

O princípio do uso da língua como moldador das representações mentais (BYBEE, 2001; 2015) é também retomado, bem como a concepção da ausência de propriedades inatas específicas à linguagem, sendo, portanto, o conhecimento linguístico resultado da interação de propriedades cognitivas gerais com a experiência (TOMASELLO, 2003; BYBEE, 2010). O conceito de não separação entre léxico e gramática e, consequentemente, o conceito de que generalizações emergem de itens do léxico são lembrados, princípios que, somados aos anteriores, divergem dos pressupostos que embasam análises apresentadas previamente no debate.

No âmbito da fonologia, o Modelo de Exemplares revisita a separação discreta entre fonética e fonologia, atribuindo substância detalhada (base fonética) à última. É com base na semelhança fonética e semântica que se organizam os itens lexicais, bem como com base em suas frequências de types e tokens. Efeitos de frequência são observados na organização fonológica, uma vez que, por exemplo, itens de alta frequência de tokens, como average e factory, mostraram-se analisados como dissilábicos em experimento avaliador de processamento linguístico ao passo que itens com menor frequência (gallery e salary) foram analisados como trissilábicos nesse mesmo experimento realizado com falantes do inglês (CONNINE; RANBOM; PATTERSON, 2008). 


\section{REVISTA DA ABRALIN}

As vantagens de uma abordagem baseada em Modelos de Exemplares são elencadas em um terceiro momento pela professora. A incorporação da produção e percepção da linguagem em um modelo uno de processamento é tida como vantajosa, bem como a ampla abrangência de sua aplicação, sendo possível estendê-la à aquisição atípica e a questões de variação e mudança linguística, por exemplo. A superação do dualismo nurture e nature configura-se como ponto positivo da abordagem apresentada, uma vez que o Modelo de Exemplares integra aspectos empíricos e sujeitos à experiência do falante a aspectos biológicos.

Entende-se aqui a relevância inegável da mesa resenhada, já que contou com a presença de ilustres professoras, além da mediação excelente do professor José Magalhães. Reconhece-se, também, a importância da merecida e belíssima homenagem à ímpar professora Leda Bisol. Ademais, é importante salientar o admirável trabalho da Abralin perante a popularização da linguística, especialmente em tempos de crise, uma vez que, sem o desenvolvimento do Abralin Ao Vivo - Linguists Online, nada disso seria possível.

\section{REFERÊECIAS}

BISOL, L. Sândi vocálico externo: degeminação e elisão. Cadernos de Estudos Linguísticos, n. 23, p. 83-101, 1992.

BYBEE, J. Phonology and language use. Cambridge: Cambridge University Press. 2001.

BYBEE, J. Language, usage and cognition. Cambridge: Cambridge University Press, 2010.

BYBEE, J. Articulatory processing and frequency of use in sound change. In: The Oxford handbook of historical phonology, 2015.

CHOMSKY, N.; HALLE, M. The sound pattern of English. Cambridge, MA: MIT Press, 1968.

CONNINE, C. M.; RANBOM, L. J.; PATTERSON, D. J. Processing variant forms in spoken word recognition: The role of variant frequency. Perception E Psychophysics, v. 70, n. 3, p. 403-411, 2008.

FONOLOGIA. Mesa redonda composta por Carmen Matzenauer, Luciani Tenani e Christina Abreu Gomes, com mediação de José Magalhães [s.l., s.n.], 2020. 1 vídeo (2h 50min 20s). Publicado pelo canal da Associação Brasileira de Linguística. Disponível em: https://www.youtube.com/watch?v=G4cPkxK8lqU. Acesso em: 04 ago. 2020.

HYMAN, L.M. Phonology: theory and analysis. New York: Holt, Rinehart \& Winston, 1975.

JOHNSON, K. Speech perception without speaker normalization: An exemplar model. In: JOHNSON, K.; MULLENIX, J. W. (Eds.) Talker variability in speech processing. San Diego: Academic Press, 1997, p. 145-165.

LEE, S. Fonologia Gerativa. In: HORA, D. da; MATZENAUER, C.L. Fonologia, Fonologias: uma introdução. São Paulo: Contexto, 2017. NESPOR, M.; VOGEL, I. Prosodic Phonology. Foris Publications, 1986.

TOMASELLO, M. Constructing a language: A usage-based theory of language acquisition. Cambridge: Harvard University Press, 2003. 